\title{
O LÚDICO NA PRÁTICA PEDAGÓGICA
}

\author{
Tânia Regina de Oliveira da Cruz ${ }^{1}$ \\ Vera Alves do Sacramento de Santana ${ }^{2}$
}

\section{Resumo}

A presente pesquisa tem como tema O Lúdico na Prática Pedagógica. A prática do professor surge no processo de aprendizagem com uma importância para o aluno, como facilitador do desenvolvimento da Alfabetização e Letramento. A função do professor não é levar conteúdos prontos para os alunos, mais conduzir a um conhecimento sólido do ponto de vista acadêmico, nesta esfera o aluno é o centro das atenções. As ações do fazer pedagógico acontecem quando se tem motivação, interesse e envolvimento de todos que estão inseridos no processo de ensino, fazendo valer o dinamismo na construção de conhecimentos.Dessa forma, pode-se concluir que o processo lúdico é uma ferramenta que contribui para o desenvolvimento do aluno no processo de ensino aprendizagem em seus primeiros anos da vida escolar. Sabemos que é preciso intensificar essa prática para que ela aconteça cotidianamente na vida escolar dos alunos, o aluno necessita ser estimulado a estudar a todo o momento e se sentir confiante no docente e no espaço físico que está inserido. Por esse prisma, o processo lúdico contribui coma educação auxiliando, professores que sempre se reinventaram,buscando inovações, desprendendo-se de idéias tradicionalistas. Fazem-se necessários criarmétodos para entreter 0 aluno na sala de aula em um ambiente saudável e amigável, porém, sem perder de vista seus objetivos didáticos na construção do saber.

\section{Palavras chaves: Lúdico; Prática; Aprendizagem;Professor.}

\begin{abstract}
This present research bascas its theme: The Ludic in the pedagogical pratic; The teacher pratic come in learning process with great importance to the student, as a facilitator of the development of literacy. The function of the professor isn't take already done content to the students, but take to a solid knowledge from the academic point of view, in this sphere the student is the center os attention. The actions of the pedagogical action happens when there's motivation, interest and involvement from all inserted in the teaching process, making the dynamism worth in the build of of knowledge. Taking that, we can conclude that the ludic process is a tool that contributes to the development of the student in the literacy tech in their first years of academic life. We know that we must intensify this pratic, so it happens on daily basis in the student life, students need to be stimulated to study all the time and must feel confidence on the professor and in the physical space that he's inserted. By this prisma, the ludic process contribute with the education, assisting professors that always reinvent themselves by seeking innovations, releasing from gestionado ideias. It's make necessary create methods to entertain the students in classroom inserted in a friendly and healthy environment, but without loose sights of your didactic objectives in building of knowledge
\end{abstract}

Key words: Ludic, Pratic, Literacy, Professor

${ }^{1}$ Doutoranda em Ciências da Educação pela Faculdade Interamericana de Ciências Sociais FICS.Mestra em Ciências da Educação pela Faculdade Interamericana de Ciências Sociais - FICS. Especialista em Docência do Ensino Superior pela Faculdade Católica de Ciências Econômicas da Bahia - FACCEBA. Especialista em Politicas Públicas pela Universidade da Integração Internacional da Lusofonia Afro - Brasileira - UNILAB. Graduada em Educação Física (licenciatura) pela Universidade Católica de Salvador- UCSAL. Professora da Rede Municipal e da Faculdade Regional de Filosofia, Ciências e Letras de Candeias - FAC.Email: taniaregina2730@gmail.com

${ }^{2}$ Mestre pela Faculdade Interamericana de Ciências Sociais- FICS. Graduada em Pedagogia pela Faculdade Regional de Filosofia, Ciências e Letras de Candeias. Especialista em Metodologia e Didática do Ensino Superior pela Faculdade São Bento da Bahia, Especialista em Alfabetização e Letramento nas Séries Iniciais, Educação de Jovens e Adultos, Especialista em Psicopedagogia Institucional ambas pela Instituição Superior de Educação de Afonso Cláudio. Docente nas Séries Iniciais do Ensino Fundamental na Prefeitura Municipal de Camaçari-Bahia. Email:joverasme@bol.com.br 


\section{Introdução}

Este artigo faz referência a experiências lúdicas no contexto escolar, ressaltando que essas práticas devem estar embasadas na proposta de oferecer aos alunos um convívio por igual, com acesso a diferentes tipos de interação social e obtenção aos mais diversos tipos de informações que the propicie 0 desenvolvimento de capacidade de ordem física, cognitiva e afetiva.

O professor deve ser valorizado de modo justo no exercício da sua profissão, pois ele propõe com que 0 aluno através da ludicidade busque 0 conhecimento.Nesse artigo, serãoapresentadas algumas abordagens que não tem como função percorrer a história da ludicidade, porém, mostrar o quanto é importante esta prática na educação.A ideia não é dizer que a solução está na prática do lúdico, mais sim, expor como mais uma ferramenta de ensino no universo pedagógico, pois:

O jogo e a brincadeira passam a ser considerados atividades indispensáveis ao desenvolvimento das capacidades e aquisição de competências essenciais para vida em sociedade, pois, mantém em seu caráter lúdico a possibilidade de fornecer subsídios para o desenvolvimento do homem (ALMEIDA, 2013, p. 20).

A experiência do lúdico apresenta indagações sobre esses momentos na escola, a partir de explicações com bases teóricas, salientando que as atividades com ludicidade proporcionam ao aluno gostar de aprender, alterando a rotina das atividades apresentadas em sala despertando o seu interesse, visto que a aprendizagem prática e lúdica permiteao aluno aumentar o interesse pelo ensino.

É necessário afirmar que o lúdico não está apenas considerando uma brincadeira qualquer, mas, como práticas que tem que assegurar os direitos da criança e suas significações no momento da ludicidade. Neste aprendizado, tem que haver um sentido de mundo em busca de um aprendizado constante e duradouro.

\section{Experiências Lúdicas no Contexto Escolar}

A instituição escolar precisa enriquecer experiências que potencializem a criança no seu desenvolvimento com aulas que englobem metodologias lúdicas para estimular sua aprendizagem. Devem ser planejadas propostas que despertem 0 conhecimento na educação infantil ensinando a construção de valores com propostas pensadas e bem elaboradas. 
Para favorecer a criança adquirir essa consciência social, criam-se estímulos que podem ser alcançadas com rotina agradável e incentivadas por brincadeiras e jogos. É necessário atividades diversificadas dentro e fora da sala de aula, para estimular o pensamento da criança.A prática do professor na sala de aula para conduzir os seus trabalhos pedagógicos com êxito, devem partir das atividades lúdicas, tendo o aluno como sujeito. Os Parâmetros Curriculares Nacionais (PCN) salienta que:

\begin{abstract}
A interação entre os alunos pode contribuir para a construção do conhecimento dos alunos. O professor deve criar uma aula interessante, que motive os alunos a aprender mais do que aquilo que já era conhecido. Cada aluno é sujeito de seu processo de aprendizagem, enquanto o professor é o mediador na interação dos alunos com os objetos de conhecimentos (BRASIL, 1998, p. 93).
\end{abstract}

As aulas planejadas contendo atividades com metodologias lúdicas precisam variar de acordo com o conteúdo a ser trabalhado, e a proposta da atividade lúdica, que será elaborada com a finalidade de promover a construção do conhecimento do aluno. É bastante atual a teoria que afirma:

\begin{abstract}
Não dá para falar de planejamento sem se perguntar a que concepção de educação o planejamento está vinculado. Isso por que a uma determinada concepção de educação correspondente uma determinada concepção de planejamento; a toda prática corresponde uma teoria e a toda teoria corresponde uma prática; podemos então dizer que não existem práticas sem intencionalidades e teorias sem autorias (DOWBOR FREIRE, 2008, $p$. 97).
\end{abstract}

Ao planejar as aulas, o docente deve preocupar-se da elaboração de suas atividades que possibilitem chegar ao objetivo proposto, construindo alternativas que incentivem a aquisição da aprendizagem, desenvolvimento, autoconfiança, organização e a interação do indivíduo. $O$ docente precisa desenvolver novos conhecimentos de forma critica reflexiva e seletiva, para efetivar uma aprendizagem significativa. Ele é um mediador dentro do processo educativo. $O$ mesmo tem que avaliar seus conhecimentos e avanços na busca de uma melhoria constante no processo do ensino e aprendizagem.

No ambiente escolar o ensino tem que ser dirigido por explanações de conteúdos que enlace atividades lúdicas que dá significados a prática do docente. $\mathrm{A}$ inserção dessas práticas favorece 0 desenvolvimento das habilidades e competências rompendo obstáculos no processo do aprender exercitando no campo da mente, pois, "a atividade lúdica é o berço obrigatório das atividades intelectuais 
da criança, sendo, por isso, indispensável à prática educativa" (PIAGET 1998, p. 160).

A escola tem o papel de buscar a cada momento, o lúdico no seu currículo, centralizando o ensino no desenvolvimento das habilidades múltiplas dos alunos, envolvendo atividades com jogos e brincadeiras, estimulando um crescimento intelectual que leve uma aprendizagem prazerosa que desperte o interesse da criança. Sabemos que o educador experimenta diferentes ferramentas na área do conhecimento como projetos educativos que motive um ensino reflexivo proporcionando o aprender, estimulando a imaginação da criança.

Do ponto de vista metodológico, pode-se dizer que transmitir conhecimento através de propostas pedagógicas lúdicas,envolve uma sequência de métodosdidáticos com novas experiências e significados exitosos. Desta forma, poderá melhorar a qualidade do ensino e as condições de trabalho dos professores. É preciso também "mudar a maneira de pensar do professor" (LORO, 2010, p. 52).

O trabalho quando é realizado com projetos de acordo com os temas transversais, fornece ao professor base para caminhar trazendo da escola um ambiente dinâmico, é uma forma de ensinar que possibilita o docente sair da rotina, além disso, o aluno troca suas experiências de forma interativa e prazerosa. A função de trabalhar com projetos é:

Tornar a aprendizagem real e atrativa, transformando a escola em um
espaço agradável, sem impor autoritariamente os conteúdos programáticos.
Assim, o aluno busca e consegue informações, lê, conversa, faz
investigações, formula hipóteses, anota dados, calcula, reúne o necessário
e, por fim, converte tudo isso em ponto de partida para a construção e
ampliação de novas estruturas cognitivas. A metodologia baseada em
projetos atrai os alunos e estimula os professores, movimentando-os,
levando-os a romper a rotina mecânica de livros didáticos e a buscar novas
ideias, soluções alternativas, criativas e inovadoras, motivando-os a 26
pesquisar novas fontes, ler diferentes gêneros, manter o olhar atento ao que
pode ser útil em sua empreitada (FONTES, 2011, p. 93).

Quando se trabalha com projetos de forma lúdica a largada começa pelos temas fazendo relações no seu desenvolvimento de forma integrada proporcionando significado na vida da criança para produzir conhecimento, pois, é de grande a relevância que as ações do projeto sejam planejadas coletivamente, ou seja, todos os atores estejam envolvidos no processo da preparação do projeto dando sugestões, propondo atividades, etc. para que todos participantes possam ter autonomia necessária para prosseguir o roteiro planejado da metodologia de projeto. 
Para que realmente aconteça de forma lúdica uma aprendizagem ativa e significativa, é imprescindível estabelecer os vários aspectos da linguagem como leituras, produções textuais dentre outras, priorizando as descobertas lúdicas. O professor neste caso é o grande mediador desta ação, proporcionandodesenvolver nos alunos suas competências e habilidades em conformidade à leitura e escrita,possibilitando a autonomia na sua construção diária de conhecimentos.

O planejamento acima de tudo é a base para que o professor possa desenvolver atividades com jogos e brincadeiras que envolvam movimentos corporais, a aprendizagem desse conteúdo compromete na elaboração do planejamento didático e pedagógico. Onde se encontram interligados fortalecendode modo eficaz a construção do saber. Desta forma pode-se ressaltar que:

O que mais caracteriza a ludicidade é a experiência de plenitude que ela
possibilita a quem a vivência em seus atos. É uma atividade onde o sujeito
integra-se à experiência sem restrições, de qualquer tipo, especialmente, as
mentais, que usualmente, tem por base juízos pré-concebidos sobre as
coisas e práticas humanas (BARRETO, 2002, p. 212).

$O$ aluno desenvolve um aprendizado quando realmente encontra significado naquilo que the é ensinado de forma prazerosa, estimular a criatividade da criança ajuda na busca de novos conhecimentos, sabendo disso, a escola the oferece subsídios para construir sua própria autonomia. A ludicidade é um elementode bastante importância nesse processo,onde a busca do saber torna-se valioso quando o aluno aprende brincando.

\section{A Ludicidade na Escola e Suas Contribuições}

A ludicidade na sua prática proporciona condições para o aluno gostar de aprender brincando manifestando uma mudançana rotina das atividades desenvolvidas na sala de aula despertando o interesse dele, pois, os alunos das novas gerações precisam de estratégias metodológicas que envolvam novas abordagens lúdicas, permite que o aluno faça da aprendizagem um processo interessante que leve a diversão.

Para isso, as atividades lúdicas devem ser planejadas com objetivos bem definidos e articulados com a proposta pedagógica da escola, auxiliando assim, na aprendizagem assimilação do conteúdo que precisa ser ministrado. Precisa ficar bem explícito que a intenção das atividades lúdicas na escola, não é sanar as lacunas que se produzem na atividade escolar diária. A incorporação do lúdico nas 
aulas justifica-se para o desenvolvimento de técnicas intelectuais e a formação de relações sociais (OLIVEIRA, 2002).

A prática educacional da pedagogia de projetos possibilita trabalhar o sujeito de forma integral estimulando sua criticidade, desenvolvendo suas múltiplas experiências de pensamentos. Tendo a ludicidade como fio condutor responsável pelo protagonismo da criança e do professor.O lúdico está sempre presente, seja para iniciar um novo conteúdo, para aprofundá-lo ou consolidá-lo ou até mesmo, para avaliar o aluno tanto nas suas interações com o outro, quanto nas competências e habilidades desenvolvidas (OLIVEIRA, 2002).

A Escola tem que inserir no seu currículo um quadro de atividades semanais que ampliem aspráticas pedagógicas envolvendo o lúdico, com o intuito de fomentar a utilização dos jogos e brincadeiras focando o direito da aprendizagem. Salienta-se que na reunião de coordenação pedagógica, os docentes devem incluir nos seus planejamentos semanais, propostas diversas para que nas atividades realizadas com as crianças, elas sejam incentivadas a interagir com os colegas e aprendam o sentido das relações individuais e coletivas.

Atualmente as pesquisas realizadas na educação, têm mostrado que as atividades lúdicas são responsáveis pelo desenvolvimento e conhecimento das crianças que fazem parte da instituição. O Referencial Curricular para Educação Infantil enfatiza a criança como ser social, psicológico e histórico, necessita do construtivismo como referencial de uma prática pedagógica (BRASIL, 1998).

Baseada nesta concepção, muitos professores, trabalham com a prática de jogos e brincadeiras no contexto educativo, que historicamenteé utilizando a ludicidade nas diversas áreas do conhecimento, buscando informações necessárias para enriquecer e aprimorar seus conhecimentos.

A Escola tem a missão de promover um ambiente sólido para que o aluno tenha boas relações de convivência e satisfação, favorecendo um despertar que seja relevante e estimule grandes conquistas. É necessário que realize em alguns momentos atividades nos mais variados ambientes da escola como, laboratório de informática, biblioteca, área de recreação, sala de jogos entre outros. Esses recursos são fundamentais para que os atores principais construam diferentes experiências durante o processo.

A Instituição de ensino para os alunos é um espaço de aprendizagem, onde o professor desempenha o papel principal tendo grande importância no 
desenvolvimento dessas experiências, contemplando os objetivos de aprendizagens desejadas no caminhar educativo, eles possuem um universo de oportunidade de troca nos mais diversos tipos de informações e experiências, é de suma importância que o ambiente escolar proporcione na criança oportunidade para desenvolver a curiosidade. É necessário que se elabore propostas com boas idéias tendo como parâmetros situações onde leve a aprendizagem significativa.

No período desse convívio a criança tem oportunidade de argumentar, relatar fatos oralmente em seqüência temporal, organizando sua fala ao contexto em que é gerado. É fácil entender que ao chegar à escola, o aluno traz uma bagagem de conhecimentos prévios que serão acrescentados naturalmente, pois, desde cedo ele manifesta o desejo de se apropriar das coisas que está em sua volta demonstrando curiosidade do mundo físico (OLIVEIRA, 2007). Conseqüentemente o mundo em que vivemos está mudando e se modernizando e a prática docente também.

Nos dias atuais os resultados são os melhores possíveis, pois, trabalhar com estratégia lúdica em sala de aula ou extraclasse, facilita o desenvolvimento, potencializando o crescimento dos alunos. Com foco nos estudos há várias vertentes demonstrando que o lúdico faz parte desse processo de globalização, os resultados são bons, pois trabalhar com essas estratégias em sala de aula ou extraclasse tem desenvolvido e potencializado um crescimento considerável no universo educacional pedagógico.

Faz-se necessário que o professor entenda que o lúdico é uma forte ferramenta aliada nessa construção do saber, e aproxima a criança do universo das aprendizagens formais e deve utilizá-lo como recursotecnológico na sua prática em sala de aula. Neste momento, vale salientar que:

O Renascimento vê a brincadeira como conduta livre que favorece o desenvolvimento da inteligência e facilita o estudo. Ao atender as necessidades infantis, o jogo infantil torna-se forma adequada para aprendizagem dos conteúdos escolares (KISHIMOTO, 2011, p.28).

O professor na sua caminhada pedagógica deve ter clareza e determinação nos seus objetivos relacionando a teoria e a prática para propor atividades lúdicas. Portanto é importante perceber que nem todo jogo leva a uma conquista, nem toda atividade lúdica será elemento de aprendizagem se não for fruto de um planejamento bem elaborado, nesta hora o professor tem que saber que as coisas acontecem de forma natural no aluno tornando mais fácil sua aprendizagem. 


\section{Considerações}

A educação no Brasil e no mundo passou por diversas modificações, diversas idéias, a sociedade está cada vez mais consciente do seu papel no que tange a educação em seus diferentes métodos de pesquisa. Diante das grandes transformações no mundo contemporâneo é certo afirmar que a aprendizagem acontece em todo caminhar da vida do homem. Com isso, sabemos que a mesma é um processo de desenvolvimento constante e continuo seja no lado pessoal, social e profissional ela deve está articulada em diversos saberes.

A instituição de ensino tem o direito e dever a todo o momento de fortalecer uma educação de qualidade, e conscientizar o homem da sua autonomia a cerca do seu papel na sociedade com pensamento crítico e reflexivo. $O$ professor consegue muito bem colocar em prática essa autonomia que a escola oferece a ele, buscando trabalhar seus conhecimentos de forma lúdica contemplando as diretrizes necessárias. Atualmente cada instituição pode escolher como ensinar seus alunos, isso vale para as duas esferas, tanto as escolas públicas como as privadas, elas desenvolvem posturas didáticas pedagógicas, visto que neste contexto cada uma tem suas classes de alunos, com suas peculiaridades, e por isso, nenhuma é igual à outra.

A prática pedagógica do professor a todo 0 momentotem que ser resignificada, a criança se beneficia, através dela, e o docente identifica os anseios de cada criança, propiciando a aplicabilidade de jogos e brincadeiras, sendo capaz de conduzir o raciocínio, além de incentivar as dinâmicas de jogos e mobilidades, incluindo os diversos domínios da inteligência cognitiva na ampliação do conhecimento. O professor no processo de alfabetização precisa ter o domínio das competências necessárias para os benefícios dos instrumentos didáticos, seu maior compromisso é garantir o interesse do aluno e sua aprendizagem.

Desta forma, ele aprende com o universo cada vez mais lúdico por que nossa sociedade é plural. Para os professores a ludicidade na sua prática, se forem bem planejadas, torna 0 aprendizado prazeroso garantindo momentos de grandes avanços com a concepção de que o sujeito interage brincando, é importante analisar as necessidades, dificuldades e as limitações, por que o principal objetivo é o desenvolvimento de cada um na sua aprendizagem. 
Através dos fundamentos teóricos estudados dos conhecimentos consolidados, trouxe uma reflexão importante dos aspectos práticos e sua contextualização, o professor na sua metodologia pedagógica deve está a cada momento buscando princípio inovador para tornar eficaz sua prática. Esse profissional da educação tem que se conscientizar que toda criança tem sua limitação, respeitando seu contexto cultural e social, para isso não podemos ter como verdade cabal que a prática lúdica pedagógica é somente uma forma de diversão, mas que possibilita o enriquecimento do aprendizado proporcionando à potencialidade do desenvolvimento das habilidades.

O aprendizado com jogos e brincadeiras são ferramentas fundamentais para o desenvolvimento cognitivo da criança, toda execução considerável é importante para o processo pedagógico da criança, pois, estimula várias competências no campo da lateralidade e motricidade dentre outros. São necessários para alfabetização esses praticáveis encorajamentos da aprendizagem no processo de construção do conhecimento no qual estamos inseridos. O lúdico na Prática Pedagógica é um instrumento de grande relevância na sociedade, que vem crescendo e tomando uma amplitude nas salas de aula.

\section{Referências:}

ALMEIDA, P. N. Educação lúdica: Teorias e práticas.São Paulo: Edições Loyola, 2013.

BARRETO, A.A. O tempo e o espaço da ciência da informação. Campinas: Transformação, 2002.

BRASIL. Referencial curricular nacional para a educação infantil/ Ministério da Educação e do Desporto, Secretaria de Educação Fundamental. - Brasília: MEC/SEF, 1998.

DOWBOR, F. F. Quem educa marca o corpo do outro.2 Ed.- São Paulo: Cortez, 2008.

FONTE, P. Projetos pedagógicos dinâmicos: a paixão de educar e o desafio de inovar. Rio de Janeiro: Wak Editora, 2011.

KISHIMOTO, T. M.Jogo, brinquedo, brincadeira e a educação. $11^{\mathrm{a}}$ ed. São Paulo, Cortez, 2011.

LORO, A. P. Formação de professores e representação sobre o brincar. 1. ed. São Paulo: Ícone, 2010

MOREIRA, D. A.Algumas variantes do método fenomenológico na pesquisa empírica. São Paulo: Pioneira, 2002.

OLIVEIRA, V. B. O Brincar e a Criança do Nascimento aos Seis Anos.4 ed. Petrópolis: Vozes, 2002.

OLIVEIRA, P. S. O que é brinquedo. São Paulo: Brasiliense, 2007.

PIAGET, J. A psicologia da criança. Ed. Rio de Janeiro: Bertrand Brasil, 1998. 